\title{
Logística reversa: estratégia para redução de custos com reuso de paletes em uma cooperativa agroindustrial
}

Ana Carla Fernandes Gasques anacarlafgasques@gmail.com Universidade Estadual de Maringá (UEM) Maringá, Paraná, Brasil

Bruno Alexandre N. Carvalho bruno_aln@outlook.com Universidade Estadual de Maringá (UEM), Maringá, Paraná, Brasil

Carlos Henrique Bulla Grigio chbgrigio@hotmail.com Universidade Estadual de Maringá (UEM), Maringá, Paraná, Brasil

Guilherme Rotta Capioto guilhermecapioto@hotmail.com Universidade Estadual de Maringá (UEM), Maringá, Paraná, Brasil

\section{Victor Hugo Salvador} vhsalvador@gmail.com Universidade Estadual de Maringá (UEM) Maringá, Paraná, Brasil

\author{
RESUMO
}

A logística permite uma visão integrada das atividades desenvolvidas dentro de uma empresa, englobando os aspectos de planejamento, implementação e controle de procedimentos envolvidos nos processos de compra, estocagem e transporte até o cliente. Seguindo o fluxo inverso, a logística reversa busca agregar valor aos produtos que serão devolvidos para as empresas, sendo utilizada como estratégia competitiva. Diante disto, o objetivo deste artigo é caracterizar a logística reversa de paletes em uma cooperativa agroindustrial evidenciando a quantidade reutilizada bem como avaliando o potencial da prática na redução de custos do setor. Para tal, a metodologia é classificada como aplicada, qualitativa, explicativa e estudo de caso. As informações foram obtidas através do sistema ERP utilizado na cooperativa e permitiu verificar a quantidade de paletes que não retornam à empresa, identificou-se, então, os principais clientes e analisou a viabilidade de se aplicar a logística reversa. Constatou-se que o retorno financeiro neste caso seria de aproximadamente $\mathrm{R} \$ 176.000,00$, que poderia ser revertido em melhorias na própria cooperativa. Além da questão financeira, a aplicação da logística reversa de paletes seria uma forma de aumentar a competitividade e imagem perante os clientes.

PALAVRAS-CHAVE: Retorno Financeiro. PBR-I. Supply Chain. 


\section{INTRODUÇÃO}

O mercado cada vez mais competitivo aliado aos consumidores mais exigentes vêm fazendo com que as empresas busquem novos mercados e/ou aprimorem seus setores operacionais (MARINHO; MARTINS, 2014). Nesse contexto, a logística é de fundamental importância dentro de uma empresa, pois permite uma visão integrada das atividades, fazendo com que as informações e os materiais se movimentem de uma maneira mais organizada e eficaz, também se destaca a importância da cadeia de suprimentos, que envolvem, fornecedores, empresas, clientes, entre outros.

Para Coelho (2010) a gestão da cadeia de suprimentos é um processo que consiste em gerenciar estrategicamente diferentes fluxos (de bens, serviços, finanças, informações) bem como as relações entre as empresas da rede, visando alcançar e/ou apoiar os objetivos organizacionais. Quanto a logística em si, ela é abordada como parte do processo da cadeia de suprimentos e não do processo inteiro.

Em uma visão mais conceitual, Bowersox e Closs (2010) relatam que a logística tem como objetivo básico disponibilizar produtos ou serviços, no lugar e no momento que estes são desejados. Assim, a logística é a integração de transporte, estoque, armazenamento, manuseio de materiais e embalagem. Decorrente de sua finalidade, a logística apresenta vantagens competitivas, oferecendo serviços diferenciados, tais como; entrega mais rápida ou agendada; montagem de produtos, gerando valor ao cliente; menor custo; propondo parcerias com fornecedores e clientes empresariais e tornando atividades e processos mais eficientes.

As formas de atingir estas vantagens competitivas é que irão definir qual tipo de estratégia específica que a empresa utilizará. Conforme ocorre o crescimento das organizações devido ao avanço tecnológico, é possível criar mais produtos em menos tempo e, em contrapartida, há a geração de resíduos decorrente da obsolescência de produtos.

Tal situação provoca preocupação com aspectos ambientais, tendo em vista os impactos que estes resíduos causam ao ambiente o (MARINHO; MARTINS, 2014). Assim, seguindo o fluxo inverso da gestão de cadeia de suprimentos, o tema central deste artigo, logística reversa, conceituada de acordo com os autores Shibao, Moori e Santos (2010) como o planejamento dos custos relacionados ao fluxo de produtos, do seu ponto de consumo até o ponto de reprocessamento, com vistas a recuperar seu valor econômico.

Ao ser utilizado como estratégia competitiva a logística reversa busca agregar valor aos produtos que deverão ser devolvidos às empresas por razões comerciais e até mesmo legais, ou reaproveitar insumos recicláveis e reutilizáveis nos processos da cadeia de suprimentos da organização (MOREIRA; GUARNIERI, 2016).

Tendo em vista a importância da reutilização de materiais e embalagens, é necessário que as organizações estabeleçam o processo de logística reversa a fim de alcançar níveis satisfatórios de serviço neste processo, aliado ao estabelecimento de um planejamento logístico e de relações colaborativas com seus clientes, para que possam atingir um diferencial competitivo dentro do mercado. 
Assim, diante do exposto, o objetivo do presente artigo é caracterizar a logística reversa de paletes em uma cooperativa agroindustrial evidenciando a quantidade reutilizada bem como avaliando o potencial da prática na redução de custos do setor. Essa pesquisa se enquadra em uma das dez áreas da Engenharia de Produção, sendo ela a Logística que, de acordo com a Abepro (2008) é o conjunto de técnicas para tratar as principais questões que envolvem transporte, movimentação, estoque e armazenamento de matéria-prima e produtos acabados, tendo por finalidade reduzir custos, garantir a disponibilidade do produto, bem como atender o nível de exigência dos clientes.

Além deste tópico referente a introdução, o artigo é composto por mais três tópicos, sendo fundamentação teórica baseada em logística em cooperativas agroindustriais, logística reversa e a logística reversa de paletes, seguido pela apresentação da metodologia adotada para a coleta e análise de dados, no quarto tópico são apresentados os resultados e a discussão do Estudo de Caso realizado em uma cooperativa agroindustrial e, por fim, as considerações finais.

\section{REFERENCIAL TEÓRICO}

\section{LOGÍSTICA EM COOPERATIVAS AGROINDUSTRIAIS}

Novas formas organizacionais vêm emergindo ao longo dos anos e de acordo com Johan, Tondolo e Corte (2016) as cooperativas agroindustriais exercem uma função fundamental no arranjo desse sistema, podendo ser vistas como meios de integrar verticalmente produtores agrícolas e pecuários e de direcionar o comércio, a industrialização e a produção de insumos.

As cooperativas, segundo Schubert e Niederle (2011), a exemplo de outras organizações, também têm objetivos econômicos, como: unir as fases de produção e de comercialização, atuar em maior escala de produção, diminuir custos em geral, adquirir fábricas, diversificar produtos, conquistar novos mercados ou novas faixas de consumidores e ampliar sua área de atuação no recebimento de matéria-prima a fim de suprir necessidades.

As cooperativas agroindustriais que gerenciam sua produção para melhorar os resultados mercadológicos e financeiros notam a importância da atividade logística no que diz respeito tanto a seu impacto nos custos quanto à sua capacidade de oferecer qualidade no suprimento de seus clientes. Em um contexto mais amplo da gestão da produção, a atividade logística é a responsável por estabelecer a ligação entre todas as atividades e processos, desde as matérias-primas até o consumidor final de um produto agroindustrial (RÉVILLION; BADEJO, 2011).

Logística é definida pelo Council of Supply Chain Management Professionals (CSCMP, 2013) como sendo o processo da cadeia de suprimentos de uma organização que engloba os aspectos de planejamento, implementação e controle de procedimentos para o transporte e armazenagem de mercadorias e serviços, tratando de movimentações de entrada e saída, internas e externas, assim como para as informações geradas durante seu processo, com o objetivo de atender aos requisitos do cliente. 
Recorrendo ao ciclo inverso da logística, a Lei no 12.305, de 02 de agosto de 2010 que instituiu a Política Nacional de Resíduos Sólidos (PNRS) (BRASIL, 2010), estabelece que a logística reversa passasse a ser lei no Brasil e consequentemente, as organizações recebem a responsabilidade pelo ciclo de vida das embalagens e materiais que compõem os respectivos produtos; e ao governo cabe a priorização da aquisição de bens que sejam reciclados ou reutilizados e daqueles que, de alguma forma, contribuam para a mitigação dos impactos socioambientais.

Tendo em vista a complexidade que envolve as cooperativas agroindustriais no que tange a sua função social, contribuição para formação de ideias, pensamentos e necessidades econômicas, entender conceitos de logística reversa torna-se imprescindível para a organização se manter competitiva no mercado e atender as legislações ambientais (JOHANN; TONDOLO; CORTE, 2016).

\section{LOGÍSTICA REVERSA}

A Logística Reversa aborda aspectos referentes ao planejamento, operação de fluxo e sistemas de informações do retorno de produtos, materiais ou embalagens ao seu respectivo centro produtivo por meio de diversos canais reversos, agregando-Ihes valor de diversas naturezas (RODRIGUES; REBELATO, 2014).

Para Fernandes (2012) a logística reversa busca possibilitar o retorno para a empresa de bens e materiais que constituem o ciclo produtivo ou de negócio, compreendendo desde a coleta de produtos de pós-consumo ou pós-venda até sua reintegração no ciclo, com o propósito de agregar valor econômico e ecológico, além de atender aspectos legais. São vários os fatores que podem iniciar o processo da logística reversa, como: devoluções de produtos; avarias e insatisfação do cliente; não cumprimento de prazos pré-acordados; retorno de embalagens; coleta seletiva e recall.

A diferença entre logística e logística reversa segundo Guarnieri (2011), se dá por meio do sentido do fluxo dos materiais, onde a logística trata do trânsito nos quais os produtos saem dos fornecedores em direção aos clientes, caracterizando um processo divergente, enquanto a logística reversa aborda o fluxo de produtos de pós-venda e pós-consumo iniciado nos clientes com destino as empresas fornecedoras, constituindo um processo convergente.

Ainda de acordo com Guarnieri (2011) o processo de logística reversa inclui atividades como o processamento do retorno de mercadorias, a reciclagem ou reutilização dos materiais das embalagens, recondicionamento ou manufatura de produtos, e descarte adequado de bens obsoletos e materiais perigosos.

Fatores como legislação, competitividade, melhoria da imagem da organização, ganhos econômicos, renovação de estoque e responsabilidade socioambiental, são para Andrade, Ferreira e Santos (2009) os principais motivos que levam as empresas a incorporarem a logística reversa em sua cadeia de suprimentos. Além disso, ela pode ser aplicada como ferramenta nas empresas para assumir uma posição socialmente responsável e ecologicamente correta, trazendo benefícios intangíveis, como o reconhecimento da sociedade, retornos financeiros e operacionais e, contribui para a imagem da empresa (PILATTI; PINCIN; NASCIMENTO, 2017). 
Já Vieira (2009) considera como o motivo mais evidente na implementação da logística reversa nas empresas o objetivo estratégico econômico ou de agregação de valor monetário, porém a competitividade, que tem como parâmetros fundamentais as exigências ecológicas e sociais, também é um motivo relevante para a execução do processo de logística reversa. Dentro deste contexto, apesar dos custos envolvidos com suas atividades, a prática da logística reversa é muito exigida pelas empresas, devido a motivações ecológicas (marketing ambiental e reponsabilidade empresarial para com o meio ambiente), legais (legislações ambientais relativas a coletas e disposição final como responsabilidade do fabricante pelo recolhimento do produto) e econômicas (diferença de preço entre matérias-primas primárias e secundárias).

O reaproveitamento de embalagens e produtos é a principal oportunidade para a recuperação de valor destes, proporcionando a obtenção de ganhos (diretos ou indiretos) pela organização, enquanto auxilia na construção de uma imagem positiva da empresa e em melhores relações com o cliente (ANDRADE; FERREIRA; SANTOS, 2009).

As atividades a serem realizadas pelo processo de logística reversa dependem do tipo de material e do motivo pelo qual o mesmo é levado a ser incorporado no processo. Em relação ao material, há dois principais grupos, o grupo de produtos, onde o fluxo de logística reversa ocorre pela necessidade de reparo, reciclagem, ou para manter estoques reduzidos nas unidades distribuidoras, e o grupo de embalagens, onde a necessidade pela logística reversa se dá principalmente em função da sua reutilização e a restrições legais relacionadas ao seu descarte (ZHANG et al., 2011).

Lacerda (2002) cita os seguintes fatores como sendo críticos e que contribuem para o desempenho do processo de logística reversa: Bons controles de entrada; Processos mapeados e formalizados; Ciclo de tempo reduzido; Sistemas de informação acurados; Rede de logística planejada; Relações colaborativas entre clientes e fornecedores. Assim, é essencial que haja controle por parte das áreas envolvidas no processo para que o fluxo da logística reversa seja viabilizado, onde é de fundamental importância o estabelecimento e a manutenção do fluxo de informações entre os fornecedores e seus clientes (JABS; ACORDES; PICHETH, 2010).

\section{LOGÍSTICA REVERSA ENVOLVENDO PALETES}

O palete, adaptação do termo inglês pallet, é uma plataforma na qual os produtos podem ser unitizados (LEANDRO, 2006). Os paletes, para Sobral (2015), são dispositivos de unitização desenvolvidos para facilitar a movimentação mecânica da produção em depósitos e para agilizar os processos de carga e descarga. O processo de unitização de acordo com Blowersox e Closs (2010) consiste no agrupamento de caixas em uma única carga, formando um só volume, otimizando o manuseio e transporte.

Os paletes podem ser constituídos por diferentes materiais, como plástico, metal, fibra, papel e madeira, sendo este último o mais tradicional (LEANDRO, 2006). As madeiras provenientes do Pinus e do Eucalipto são as mais indicadas para a fabricação dos paletes (SOBRAL, 2015). Pelo fato do uso de paletes aumentar ano a ano em todo o mundo, estima-se que para 2020 haverá déficit 
no suprimento de toras de Pinus, pois as áreas de reflorestamento não acompanham a demanda, aumentando, desta maneira, o custo com a aquisição de paletes (JABS; ACORDES; PICHETH, 2010; DURACCIO; ELIA; FORCINA, 2014).

Além do aumento de custo, existe outro problema, o descarte desses paletes, habitualmente eles são incinerados eliminando gases e fumaças afetando diretamente o meio ambiente (LEANDRO, 2006; ORTIZ; SELLITTO, 2013; MELLO; ANUNCIAÇÃO, 2015).

De acordo com Jabs, Acordes e Picheth (2010) essas adversidades enfrentadas pelas empresas juntamente com o processo de globalização e a mudança da percepção dos clientes têm promovido uma busca por novos conceitos logísticos como forma de adequação ao padrão de concorrência, para garantir a lucratividade e sobrevivência no mercado. É nesta busca por novos conceitos logísticos que a logística reversa envolvendo paletes vem recebendo uma maior atenção das empresas e de pesquisadores, os quais procuram diferentes métodos para o reaproveitamento de paletes; redução dos resíduos gerados durante $\mathrm{o}$ uso e principalmente redução dos custos envolvidos (LEANDRO, 2006; ORTIZ; SELLITTO, 2013; DURACCIO; ELIA; FORCINA, 2014; MELLO; ANUNCIAÇÃO, 2015).

Para que o processo de logística reversa de paletes seja eficiente e eficaz é necessária uma boa comunicação e troca de informações entre fornecedores e clientes, pois como mencionado no estudo de Sabbadini, Pedro e Barbosa (2005) a não devolução dos paletes pelos clientes atacadistas, juntamente com a falta de controle efetivo do retorno dos paletes gerava uma perda estimada na ordem de $45 \%$ ao longo do ano em uma indústria de bebidas destiladas. Estas perdas foram reduzidas para $20 \%$ a partir do mapeamento dos processos e da coleta de informações dos fornecedores e clientes (SABBADINI; PEDRO; BARBOSA, 2005).

Jabs, Acrodes e Picheth (2010) analisaram o potencial do retorno de paletes de uma indústria de papel, visto que a empresa não realizava nenhum procedimento para retorno dos paletes. Os autores através da aplicação do sistema de coleta programada Milk run e da venda de paletes impróprios para reuso estimaram um retorno anual acima de $R \$ 39.000,00$ (trinta e nove mil reais) e a preservação de cerca de 380 árvores que serviriam para a produção de novos paletes.

Em relação aos resíduos gerados principalmente pela queima dos paletes Leandro (2006) mostra a solução encontrada por uma distribuidora de bebidas, na qual os gestores logísticos conseguiram parceiros para reutilizar os paletes que antes eram incinerados, desta forma a empresa diminuiu seus resíduos e seu impacto ambiental.

Ortiz e Sellitto (2013) relatam que a redução de resíduos de madeira dos paletes de uma empresa metalmecânica foi possível após mudanças dos métodos de trabalho que inicialmente envolveu a conscientização das pessoas de diferentes departamentos da empresa; seguida de reuniões com os departamentos de produção, logística, compras e ambiental, nas quais foram definidos objetivos, divisão de atividades e levantamento da produção de resíduos e gastos com paletes; visita e reunião com a empresa fornecedora de paletes para discutir a possibilidade de reutilização dos paletes. Com essa proposta a empresa metalmecânica teve um ganho econômico de cerca de $\mathrm{R} \$ 200.000,00$ (duzentos mil reais) no ano. 


\section{PROCEDIMENTOS METODOLÓGICOS}

Este artigo é dividido em duas partes: a primeira consiste em uma revisão de literatura e a segunda em um estudo de caso. De acordo com a classificação feita por Prodanov e Freitas (2013) o presente trabalho enquadra-se como sendo uma pesquisa de natureza aplicada; qualitativa quanto à forma de abordagem do problema; explicativa quanto aos fins da pesquisa e que utiliza o estudo de caso como procedimento para o desenvolvimento da pesquisa. Yin (2015) define estudo de caso como uma investigação empírica que avalia um fenômeno contemporâneo que procura explicar "como" ou "por que" ele ocorre.

A revisão literária sobre os assuntos pertinentes aos temas da pesquisa será realizada para fornecer embasamento teórico e contextualização do estudo. Segundo Prodanov e Freitas (2013) após a escolha do tema é necessário fazer um levantamento das fontes teóricas na forma de uma revisão bibliográfica com objetivo de contextualizar e fornecer subsídios para o desenvolvimento da pesquisa.

O estudo de caso foi realizado em uma Cooperativa Agroindustrial com sede na cidade de Maringá-PR, onde foram coletados dados referentes à utilização e reutilização de paletes, assim como, os custos envolvidos nestas atividades. Após a coleta dos dados foi feito um mapeamento do cenário atual do setor e com base neste cenário foram propostas ações de melhorias para otimização no uso dos paletes, reuso dos mesmos e, concomitantemente com redução dos custos atuais.

Os dados utilizados neste estudo foram coletados do sistema ERP (Enterprise Resource Planning) utilizado pela cooperativa e são referentes às informações dos meses de janeiro a setembro do ano de 2016, período em qual o preço de compra de um palete era de $\mathrm{R} \$ 25,00$.

Para obtenção da quantidade de paletes retornados em uma viagem foram analisadas duas restrições: dimensões e capacidade máxima do caminhão transportador. $O$ número máximo de paletes retornados tendo como restrição o limite das dimensões foi calculado de acordo com a equação 1 , onde NP é número de paletes.

$$
N P=\left(\frac{\text { CompCam }}{\text { CompPal }}\right) *\left(\frac{\text { LargCam }}{\text { LarPal }}\right) *\left(\frac{\text { AltCam }}{\text { AltPal }}\right)
$$

A quantidade de paletes tendo como restrição o limite da capacidade de transporte é encontrada a partir da equação 2 .

$$
N P=\left(\frac{\text { CapMaxCam }}{\text { PesoUnitPal }}\right)
$$


As análises estatísticas e gráficos foram feitas utilizando software aplicativo Microsoft Excel ${ }^{\circledR}$.

\section{ESTUDO DE CASO}

A cooperativa, objeto desta pesquisa foi fundada há 54 anos no município de Maringá, estado do Paraná, com o objetivo de organizar a produção regional de café. Porém com a expansão dos negócios da cooperativa, houve o início da produção de óleo de soja em 1979, e de bebidas à base de soja, néctares de frutas e molhos alimentícios em 2003, produtos estes que fazem parte do departamento de varejo. Estes produtos são enviados aos clientes com o uso de paletes, assim como também são utilizados nos processos internos dos setores de Produção e Movimentação e Armazenagem para efetuar o transporte de matérias-primas, materiais diversos, produtos semiacabados e acabados.

O processo de logística reversa de paletes na cooperativa inicia-se com um levantamento realizado pelo setor de Logística de Varejo das quantidades de paletes em posso dos clientes, informação que é repassada para o departamento Comercial, que por sua vez realiza o contato com estes clientes, com o objetivo de combinar a coleta dos paletes, e uma vez aceito o recolhimento, uma transportadora contratada pela cooperativa realiza o serviço.

Analisando as informações do período da pesquisa, observa-se que os paletes enviados para clientes totalizaram 34.832 unidades, enquanto que apenas 7.730 retornaram para a cooperativa, permanecendo 27.102 paletes nos clientes, o que representa um potencial de ganho total de $\mathrm{R} \$ 677.550,00$. O Gráfico 1 exibe o percentual de retorno durante o período avaliado.

Figura 1 - Percentual de paletes retornados para a cooperativa

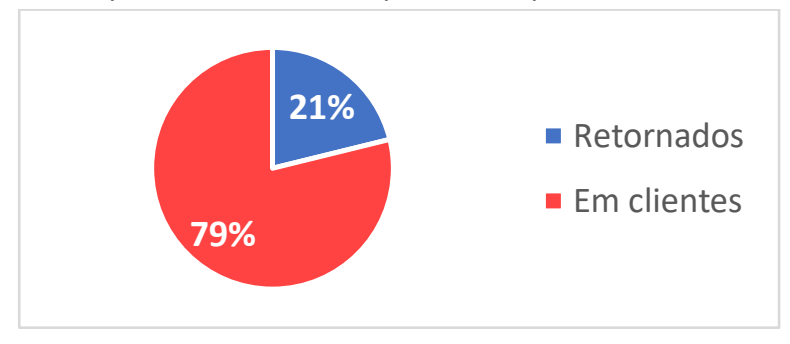

Fonte: Autoria própria (2018)

Os clientes para os quais são enviados os paletes com produtos acabados encontram-se em 8 estados brasileiros: Paraná; São Paulo; Rio de Janeiro; Santa Catarina; Rio Grande do Sul; Minas Gerais; Espirito Santo e Mato Grosso do Sul. Dentre todos os clientes da cooperativa, foram identificados $270 \mathrm{com}$ um saldo de paletes a serem retornados. 0 Gráfico 2 aponta os principais estados para o qual são enviados os paletes assim como a quantidade de retorno dos mesmos. 
Figura 2 - Quantidade de paletes enviados e retornados por estado

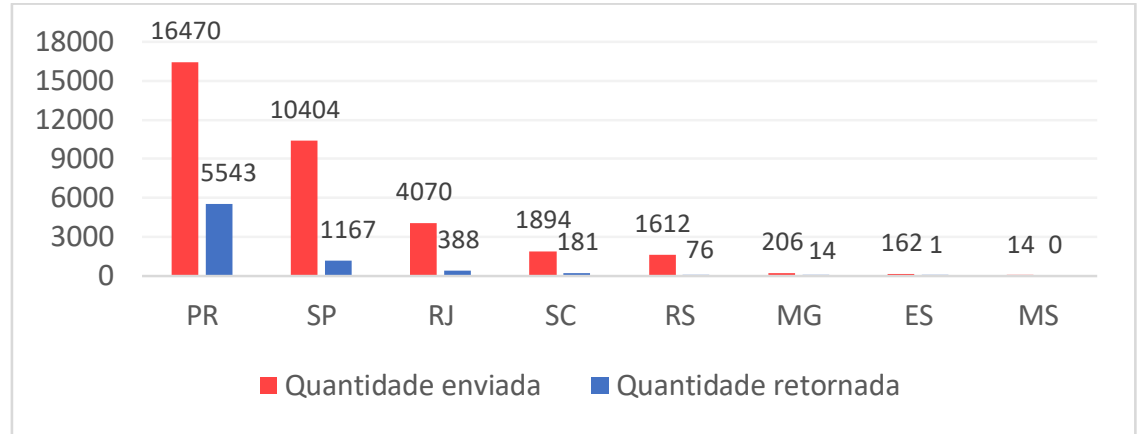

Fonte: Autoria própria (2018)

Apenas os clientes presentes nos estados do Paraná, São Paulo e Rio de Janeiro representam juntos $88,84 \%$ de toda a quantidade recebida de paletes, com o Paraná possuindo maior índice de envio, aproximadamente 47,28\%, seguido por São Paulo com $29,87 \%$ e Rio de Janeiro, com $11,68 \%$. Consoante com esses valores, os três estados são os que possuem as maiores quantidades de paletes não retornados a cooperativa, totalizando $86,83 \%$ da quantidade a ser retornada.

Com o objetivo de estratificar os dados e viabilizar a avaliação do potencial econômico da logística reversa dos paletes, foram listadas e selecionadas as quatro cidades, pertencentes a estes estados, onde encontram-se os clientes com as maiores parcelas de paletes não retornados. A Tabela 1 exibe as quatro cidades identificadas segundo este parâmetro.

Tabela 1 - Cidades com os maiores números de paletes em posse de clientes

\begin{tabular}{ccccc} 
Estado & Cidade & Paletes enviados & Paletes retornados & Paletes em clientes \\
PR & Cafelândia & 10077 & 4240 & 5837 \\
RJ & Rio de Janeiro & 1979 & 216 & 1763 \\
SP & São Paulo & 1126 & 76 & 1050 \\
PR & Curitiba & 641 & 5 & 636 \\
\hline
\end{tabular}

Fonte: Autoria própria (2018)

Para que fosse possível o cálculo do gasto com transporte destes paletes para a realização da logística reversa, foram buscadas as distâncias entre as cidades da Tabela 1 e a cidade de Maringá, local onde se encontra o complexo industrial da cooperativa de onde são expedidos os produtos acabados assim como os paletes. A Tabela 2 apresenta estas distâncias:

Tabela 2 - Distância entre Maringá e as cidades selecionadas

$\begin{array}{ccc}\text { Cidade de origem } & \text { Cidade- } & \text { Distância }(\mathrm{Km}) \\ & \text { Clestino } & 249 \\ \text { Maringá } & \text { Rio de Janeiro } & 1074 \\ & \text { São Paulo } & 636 \\ & \text { Curitiba } & 426\end{array}$

Fonte: Autoria própria (2018) 
Foram levantados também os valores pagos à transportadora que presta serviço para a cooperativa pelo frete para as quatro cidades (Cafelândia, Rio de Janeiro, São Paulo e Curitiba) durante o período analisado. Os valores levantados são em relação ao transporte de cargas utilizando um caminhão Truck. A média destes custos e o custo por quilometro a cada cidade são exibidos na Tabela 3.

Tabela 3 - Preço médio do frete em um caminhão truck para as cidades selecionadas

cidade de origem

Maringá
Cidade destino Valor (RS) RS/ Km

Cafelândia $\quad \mathrm{R} \$ 1.813,19 \mathrm{R} \$ 7,28$

Rio de Janeiro $\mathrm{R} \$ 3.797,32 \mathrm{R} \$ 3,53$

São Paulo R\$2.340,20 R\$3,67

Curitiba $\quad R \$ 1.426,28 \quad R \$ 3,34$

Fonte: Autoria própria (2018)

Os caminhões utilizados no transporte de cargas da cooperativa apresentam 14 metros de comprimento, 2,5 metros de largura e 2,7 metros de altura com capacidade máxima de 14 toneladas. Já os paletes transportados são do tipo PBRI (Palete Padrão Brasil) com dimensões $1,00 \times 1,20 \times 0,146 \mathrm{~m}$ e peso médio de 35 $\mathrm{kg}$.

Com base nessas informações, analisou-se o número de paletes transportados em relação as dimensões do caminhão através da equação 1 , que totalizou 504 paletes, no entanto, o peso total ultrapassa a capacidade máxima do caminhão truck. Desta forma, utilizou-se a equação 2 , pois havia limite de peso, para encontrar o número máximo possível de 400 paletes retornados por viagem.

A viabilidade para a aplicação desse processo de logística reversa pela cooperativa foi analisada em relação ao retorno financeiro dado pela diferença entre o valor dos paletes retornados e custo total do frete. A Tabela 4 mostra os resultados obtidos para as quatro cidades com maior saldo devedor de paletes.

Tabela 4 - Retorno financeiro da logística reversa de paletes

\begin{tabular}{|c|c|c|c|c|c|}
\hline Cidades & $\begin{array}{c}\text { Saldo } \\
\text { devedor de } \\
\text { paletes } \\
\text { (un.) }\end{array}$ & $\begin{array}{l}\text { Valor total } \\
\text { dos paletes } \\
\text { (VP) (R\$) }\end{array}$ & $\begin{array}{c}\text { Número } \\
\text { de } \\
\text { viagens }\end{array}$ & $\begin{array}{c}\text { Custo total } \\
\text { do frete (CT) } \\
\text { (R\$) }\end{array}$ & $\begin{array}{c}\text { Retorno } \\
\text { financeiro (VP } \\
\text { - CT) (R\$) }\end{array}$ \\
\hline Cafelândia & 5837 & $145.925,00$ & 15 & $27.197,85$ & $118.727,15$ \\
\hline Rio de Janeiro & 1760 & $44.000,00$ & 5 & $18.986,60$ & $25.013,40$ \\
\hline São Paulo & 1050 & $26.250,00$ & 3 & $7.020,60$ & $19.229,40$ \\
\hline Curitiba & 636 & $15.900,00$ & 2 & $2.852,56$ & $13.047,44$ \\
\hline Total & 9283 & $232.075,00$ & 25 & $56.057,61$ & $176.017,39$ \\
\hline
\end{tabular}

Fonte: Autoria própria (2018)

O possível retorno financeiro através da logística reversa de paletes apenas nessas cidades é de aproximadamente $\mathrm{R} \$ 176.000,00$ (cento e setenta e seis mil) reais (Tabela 4), valor que poderia ser investido em melhorias internas tanto estruturais quanto dos processos produtivos na própria cooperativa. Além desse retorno, há também uma redução na necessidade de compra de novos paletes, 
pois possivelmente uma parcela dos paletes retornados poderia ser reutilizada, tornando a economia ainda maior.

Mas para que esta prática seja realmente desenvolvida pela cooperativa de forma eficiente e eficaz é necessária uma boa comunicação e troca de informações com seus clientes, estreitando as relações entre fornecedor e consumidor gerando benefícios a ambos. A cooperativa poderia firmar acordos com seus clientes para o agendamento da devolução dos paletes ou ainda desenvolver algum método de recolhimento sem custos adicionais às partes envolvidas.

\section{CONSIDERAÇÕES FINAIS}

A logística reversa de paletes se aplicada corretamente poderá trazer inúmeras vantagens para a cooperativa, como melhorar a competitividade frente aos concorrentes; incremento da receita, pela menor necessidade de compra de novos paletes; contribuição com o meio ambiente através do reuso dos paletes e todos esses fatores podem melhorar a imagem da cooperativa perante os clientes e a sociedade em geral.

Constatou-se que o processo de logística reversa de paletes na cooperativa tem início com o setor de Logística de Varejo, que identifica a quantidade existente com clientes e repassa a informação ao departamento Comercial, que entra em contato a fim de combinar a coleta dos paletes. Uma vez efetivado o recolhimento, uma transportadora terceirizada realiza o serviço. Apenas $22 \%$ do total de paletes enviados a clientes retornam à cooperativa, representando em perdas por não reutilização destes e, consequentemente, compra de novos.

Neste trabalho considerou-se apenas a viabilidade econômica do retorno dos paletes, não analisando as perdas pela quebra de paletes ou o seu custo de restauração. Desta maneira, novos estudos referentes ao tema se tornam necessários para uma melhor observação dos benefícios da logística reversa aplicada a paletes. 


\title{
Reversal Logistics: strategy reducing costs with potential reuse in an agroindustrial cooperative
}

\begin{abstract}
Logistics allows an integrated view of the activities developed within a company, encompassing aspects of planning, implementation and control of procedures involved in the processes of purchase, stocking and transportation to the customer. Following the reverse flow, reverse logistics seeks to add value to the products that should be returned to the companies, being used as a competitive strategy. The objective of this article is to characterize the reverse logistics of pallets in an agro industrial cooperative, evidencing the quantity reused as well as evaluating the potential of the practice in the reduction of costs of the sector. The information was obtained from the ERP system used in the cooperative and allowed to verify the quantity of pallets that do not return to the company, identified the main customers and analyzed the feasibility of applying reverse logistics. The financial return in this case would be approximately $R \$ 176,000.00$, which could be reversed in improvements in the cooperative itself. In addition to the financial issue, the application of reverse pallet logistics would be a way to increase competitiveness and image vis-à-vis customers.
\end{abstract}

KEYWORDS: Magazine. Articles. Formatting. 
ABEPRO - ASSOCIAÇÃO BRASILEIRA DE ENGENHARIA DE PRODUÇÃO. Áreas e subáreas de Engenharia de Produção. 2008. Disponível em:

$<$ https://www.abepro.org.br/interna.asp?p=399\&m=424\&ss=1\&c=362>. Acesso em 27 de set. de 2017.

ANDRADE, E. M.; FERREIRA, A. C.; SANTOS, F. C. A. Tipologia de sistemas de logística reversa baseada nos processos de recuperação de valor. In: Simpósio de Administração da Produção, Logística e Operações Internacionais. São Paulo, 2009.

BOWERSOX, D. J.; CLOSS, D. J. Logística Empresarial: o processo de integração da cadeia de suprimento. São Paulo: Atlas, 2010.

BRASIL. Política Nacional de Resíduos Sólidos. Lei № 12.305, de 2 de agosto de 2010. Presidência da República - Casa Civil. Disponível em: < http://www.planalto.gov.br/ccivil_03/_ato2007-2010/2010/lei//12305.htm>. Acesso em: 20 set. 2017.

COUNCIL OF SUPPLY CHAIN MANAGEMENT PROFESSIONALS. Supply Chain Management Terms and Glossary, 2013. Disponível em: <https://cscmp.org/imis0/CSCMP/>. Acesso em: 20 de dezembro de 2016.

COELHO, L. C. Gestão da Cadeia de Suprimentos - conceitos, tendências e ideias para melhoria. Today Logistics, São Paulo, n. 51, ago. 2010.

DURACCIO, V.; ELIA, V.; FORCINA, A. Na Activity based Costing Model for Evaluating Effectiveness of RFID Technology in Pallet Reverse Logistics System. Proceedings of the International Conference on Numerical Analysis and Applied Mathematics. 2014. crossref

FERNANDES, K. S. Logística: Fundamentos e Processos. 1. ed. Curitiba: IESDE Brasil, 2012. $160 \mathrm{p}$.

GUARNIERI, P. Logística Reversa: Em Busca do Equilíbrio Econômico e Ambiental. 1. ed. Recife: Clube dos Autores, 2011. 307 p.

JABS, R. J.; ACORDES, A. F.; PICHETH, A. L. Logística Reversa Como Instrumento de Melhoria nos Âmbitos Econômico, Ambiental e Social: Aplicação do Fluxo Reverso de Paletes em Uma Empresa do Setor de Embalagens de Papel. In: Encontro Nacional de Engenharia de Produção, São Carlos, 2010. Disponível em: $<$ http://www.abepro.org.br/biblioteca/enegep 2010_tn_sto_113_741_14789.pdf>. Acesso em: 20 set. 2017. 
JOHANN, D.; TONDOLO, R. R. P.; CORTE, V. F. D. O Papel da Cooperativa na Logística Reversa de Embalagens de Agrotóxicos. Revista de Administração do Sul do Pará (REASP), v. 3, n. 1, 2016.

LACERDA, L. Logística reversa, uma visão sobre os conceitos básicos e as práticas operacionais. Centro de Estudos em Logística - COPPEAD, UFRJ - 2002. Disponível em: <http://www.ecodesenvolvimento.org/biblioteca/artigos/logistica-reversauma-visao-sobre-os-conceitos/attachment_download/arquivo>. Acesso em: 20 set. 2017.

LEANDRO, F. Logística Reversa: Percentual de Ocupação dos Paletes na Carga e os Custos de Retorno. Management: Revista de Ciências Empresariais, Maringá, v.3, n.1, p.17-25, 2006.

MARINHO, J. C. R. L.; MARTINS, M. F. Mensuração dos custos de operações reversa de reciclagem: Estudo de caso numa empresa do setor de plástico em Campina Grande - PB. Revista Gestão Industrial, Ponta Grossa, v. 10, n. 4, p. 810-829, 2014. crossref

MELLO, M. F.; ANUNCIAÇÃO, M. A. Logística Reversa de Paletes - Um Estudo de Caso. Engevista. v.17, n.1, p.136-151, 2015. crossref

MOREIRA, I. F.; GUARNIERI, P. Preferência dos consumidores por empresas que implementam práticas de logística reversa como meio de fidelização: Estudo na indústria de cosméticos brasileira. Revista Gestão Industrial, Ponta Grossa, v. 12, n. 4, p. 171-192, 2016.

crossref

ORTIZ, J. P.; SELLITTO, M. A. Redução de Resíduos Sólidos na Indústria: o Caso dos Paletes em uma Empresa Metal-Mecânica. Revista Liberato. v.14, n.21, p.77-90, 2013. crossref

PILATTI, L. E; PICININ, C.T.; NASCIMENTO, R. F. O cenário da logística reversa em empresas multinacionais do município de Ponta Grossa - PR de 2010 a 2012. Revista Gestão Industrial, Ponta Grossa, v. 13, n. 1, p. 120-136, jan. /mar. 2017. crossref

PINHO, D. B. Economia e Cooperativismo. São Paulo: Saraiva, 1977.

PRODANOV, C. C.; FREITAS, E. C. Metodologia do trabalho científico: métodos e técnicas da pesquisa e do trabalho acadêmico. 2.ed. Novo Hamburgo: Feevale, 2013. 277p. 
RÉVILLION, J. P. P.; BADEJO, M. S. Gestão e Planejamento de Organizações Agroindustriais. Universidade Federal do Rio Grande do Sul - UFRGS, 1. Ed. Porto Alegre: Editora da UFRGS, 2011.

RODRIGUES, A. M.; REBELATO, M. G. Proposta de um referencial metodológico para a avaliação de processos de logística reversa de produtos pós-venda em empresas industriais. Revista Gestão Industrial, Ponta Grossa, v. 10, n. 3, p 673699, 2014. crossref

ROGERS, D. S.; TIBBEN-LEMBKE, R. S. Going Backwards: Reverse Logistics Trends and Practices. University of Nevada, Center for Logistics Management. Reverse Logistics Executive Council, 1998.

SABBADINI, F. S.; PEDRO, J. V.; BARBOSA, P. J. O. A Logística Reversa no Retorno de Pallets de uma Indústria de Bebidas. Anais... III Simpósio de Excelência em Gestão e Tecnologia - SEGeT, 3, p.747-755, 2005.

SCHUBERT, M. N.; NIEDERLE, P. A. A competitividade do cooperativismo de pequeno porte no sistema agroindustrial do leite no oeste catarinense. Interfaces em Desenvolvimento, Agricultura e Sociedade - IdeAS, v. 5, n. 1, jan./jun. 2011.

SHIBAO, F.; MOORI, R.; SANTOS, M. R. A Logística reversa e a sustentabilidade Empresarial. In: Seminários Em Administração. São Paulo, 2010.

SOBRAL, F. H. A. Técnicas de Unitização de Cargas em Paletes. São Paulo: Interlogis - Logística e Embalagens, 2015. 48p.

VIEIRA, F. H. Gestão de Estoques e Operações Industriais. 1. ed. Curitiba: IESDE Brasil, 2009. 316 p.

YIN, R. K. Estudo de Caso: Planejamento e Métodos, 5.ed. Porto Alegre: Bookman, 2015. 290p.

ZHANG, T., CHU, J., WANG, X., LIU, X., CUI, P. Development pattern and enhancing system of automotive components remanufacturing industry in China. Resources, Conservation and Recycling, v. 55, n.6, p. 613-622, 2011. crossref

ZYLBERSZTAJN, D. Organização de Cooperativas: desafios e tendências. Revista de Administração, v. 29, n. 3, 1994. 
Recebido: 11 Set. 2018

Aprovado: 09 Mar. 2019

DOI: 10.3895/gi.v15n3.8818

Como citar:

GASQUES, A. C. et al. Logística reversa: Estratégia Para Redução De Custos Com Reuso De Paletes Em

Uma Cooperativa Agroindustrial. R. Gest. Industr., Ponta Grossa, v. 15, n. 3, p. 169-184, Jul./Set. 2019.

Disponível em: http://periodicos.utfpr.edu.br/revistagi . Acesso em:

Correspondência:

Ana Carla Fernandes Gasques

Universidade Estadual de Maringá (UEM), Maringá, Paraná, Brasil.

Direito autoral: Este artigo está licenciado sob os termos da Licença Creative Commons-Atribuição 4.0 Internacional.

\section{(c) (1)}

